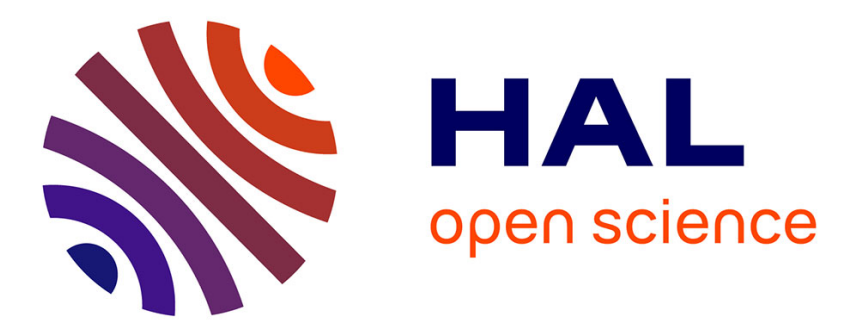

\title{
Structure in Nascent Carbon Nanotubes Revealed by Spatially Resolved Raman Spectroscopy
}

Perine Landois, Mathieu Pinault, Mickaël Huard, Valérie Reita, Stéphan Rouzière, Pascale Launois, Martine Mayne-L'Hermite, Nedjma Bendiab

\section{- To cite this version:}

Perine Landois, Mathieu Pinault, Mickaël Huard, Valérie Reita, Stéphan Rouzière, et al.. Structure in Nascent Carbon Nanotubes Revealed by Spatially Resolved Raman Spectroscopy. Thin Solid Films, 2014, 568, pp.102-110. 10.1016/j.tsf.2014.07.016 . hal-01003939

\section{HAL Id: hal-01003939 \\ https://hal.science/hal-01003939}

Submitted on 10 Jun 2014

HAL is a multi-disciplinary open access archive for the deposit and dissemination of scientific research documents, whether they are published or not. The documents may come from teaching and research institutions in France or abroad, or from public or private research centers.
L'archive ouverte pluridisciplinaire HAL, est destinée au dépôt et à la diffusion de documents scientifiques de niveau recherche, publiés ou non, émanant des établissements d'enseignement et de recherche français ou étrangers, des laboratoires publics ou privés. 


\section{Structure in Nascent Carbon Nanotubes Revealed by Spatially Resolved Raman Spectroscopy}

Périne Landois ${ }^{1,2, \dagger}$, Mathieu Pinault ${ }^{1}$, Mickaël Huard ${ }^{2}$, Valérie Reita ${ }^{3}$, Stéphan Rouzière ${ }^{2}$, Pascale Launois ${ }^{2}$, Martine Mayne-L'Hermite ${ }^{1}$, Nedjma Bendiab ${ }^{3, *}$

${ }^{1}$ CEA, IRAMIS, SPAM, Laboratoire Francis Perrin (CNRS URA 2453), 91191 Gif-surYvette, France

${ }^{2}$ Laboratoire de Physique des Solides, UMR CNRS 8502, Université Paris Sud 11, 91405 Orsay, France

${ }^{3}$ Univ. Grenoble Alpes, Inst NEEL, F-38042 Grenoble, France

CNRS, Inst NEEL, F-38042 Grenoble, France

$\dagger$ Present address: Laboratoire Charles Coulomb, UMR5221, Université Montpellier II, Place Eugene Bataillon, 34095 Montpellier, France

*Corresponding author: nedjma.bendiab@grenoble.cnrs.fr; Phone: +33 4 56387074; Fax: +33 476881191. 


\begin{abstract}
:
The understanding of carbon nanotubes (CNT) growth is crucial for the control of their production. In particular, the identification of structural changes of carbon possibly occurring near the catalyst particle in the very early stages of their formation is of high interest. In this study, samples of nascent CNT obtained during nucleation step and samples of vertically aligned CNT obtained during growth step are analysed by combined spatially resolved Raman spectroscopy and X-Ray diffraction measurements. Spatially resolved Raman spectroscopy reveals that iron-based phases and carbon phases are co-localised at the same position, and indicates that $\mathrm{sp}^{2}$ carbon nucleates preferentially on iron-based particles during this nucleation step. Depth scan Raman spectroscopy analysis, performed on nascent CNT, highlights that carbon structural organisation is significantly changing from defective graphene layers surrounding the iron-based particles at their base up to multi-walled nanotube structures in the upper part of iron-based particles.
\end{abstract}

Keywords: Aligned-MWNT, spatially resolved Raman spectroscopy, mapping, colocalisation, X-Ray microdiffraction. 


\section{Introduction:}

Aligned multi-walled carbon nanotubes (A-MWNT) are promising nanostructured networks for a large range of applications in various fields such as separation or filtration [1], supercapacitors [2], composite materials [3,4]. They are mainly prepared by CVD (Chemical Vapour Deposition) processes involving, either a deposition of a metal film before the reaction with a carbonaceous source [5-7], or the formation of catalyst particles from a metal precursor which is injected together with the carbon precursor [8-11]. Concerning this later method, liquid precursors are generally injected in the reactor either with syringes or as liquid aerosols and A-MWNT are subsequently grown with, generally, a high growth rate and almost no by-products (amorphous carbon) among nanotubes [8-12]. Such processes offer the advantage to be continuous and to be easily scalable. Their development, in order to extend their potentialities, is strongly related to the precise control of carbon nanotube (CNT) growth which is a direct result of the understanding of their growth mechanisms. This is one of the motivations for the study of nanotube formation which has been widely investigated by researchers all over the world [13]. Ex-situ physico-chemical analyses of samples synthesized under precise conditions are focused on the size and shape of catalyst particles as well as on their physical state and their chemical composition and structure [11, 14-16]. The analysis of carbon in such samples has been also investigated by different techniques such as electron microscopy (SEM or TEM), Raman spectroscopy, X-Ray Diffraction or X-Ray Photoelectron Spectroscopy [11, 15, 17-19]. Nevertheless, complementary information regarding global quantitative carbon structure changes occurring on nanotubes near the catalyst particles, from the CNT nucleation step up to the CNT growth step, still need to be completed.

Our previous works regarding A-MWNT carpet synthesised by aerosol-assisted CCVD (Combustion Chemical Vapor Deposition) process studied through ex-situ analysis demonstrated that (i) different iron-based phases are occurring in the same sample $[15,19]$, 
(ii) iron oxide is formed during the cooling step [15], (iii) nanotubes are obtained through a base-growth mechanism $[11,20]$. X-Ray diffraction allows one to quantify the alignment degree of nanotubes in macroscopic carpets $[19,21]$. Raman spectroscopy demonstrates that such nanotubes exhibit a high structural quality as compared to nanotubes generally grown by CVD [12], and XPS experiments (X-rays Photoelectron Spectroscopy), performed on samples resulting from the early stages of nanotube growth, show the occurrence of $\mathrm{sp}^{2}$ carbon in the early stages of CNT growth [11]. More recently, in-situ X-ray diffraction experiments on AMWNT carpet synthesised by aerosol-assisted CCVD process allowed us to show that particles giving rise to CNT growth are cementite nanoparticles [22].

The present study couples global and local analysis, based on ex-situ X-ray diffraction and en Raman spectroscopy. The recent developments in spatially resolved Raman spectroscopy allowed us to analyse samples obtained during CNT nucleation step (very early stages of CNT synthesis), formed of nascent CNT on the catalyst particles. Thus, it was possible to get Raman mapping of both catalyst nanoparticles and CNT. Our work gives evidence of carbon structural changes between nucleation and growth stages. By analysing the D and G band obtained on CNT samples produced during the nucleation step, we report that carbon structural organisation is significantly changing from defective graphene layers surrounding the particles at their base up to multi-walled nanotube structures in the upper part of particles. Alignment of CNT, as determined by X-ray diffraction, differs between the CNT nucleation and growth step.

\section{Experimental Section}

Aligned carbon nanotube samples are synthesized by aerosol-assisted catalytic chemical vapour deposition (AA-CCVD) from toluene and ferrocene precursors [12, 20]. The synthesis set-up and standard procedure have been described previously [9, 17]. Briefly, the precursor 
mixture is made of ferrocene $(2.5$ wt. \%) dissolved in toluene, the resulting solution is injected through an aerosol and carried by a helium flow (purity 99.999; oxygen impurities 3 ppm-mol $\mathrm{H}_{2} \mathrm{O}$ and 2 ppm-mol $\mathrm{O}_{2}$ ) in the reactor heated at $850{ }^{\circ} \mathrm{C}$ and placed at atmospheric pressure. The cooling step is also performed under helium (same quality). This flexible technique allowed us to control the CNT length thanks to the duration of the continuous injection of precursors and thus to obtain different samples at different growth steps of the CNT. It is important to note that even if the metal catalyst source is injected continuously, the resulting A-MWNT carpets exhibit a high purity with almost no catalyst particles deposited in between the MWNT.

For this study two types of samples are obtained corresponding to two key steps of the growth chronology with different AA-CCVD durations. The first one (sample 1) is obtained after 15 seconds of synthesis and the second one after 15 minutes corresponding respectively to MWNT nucleation and growth steps. These two samples are then cooled down [15].

The general morphology and arrangement of the resulting CNT samples were examined in a field emission scanning electron microscope (FEG-SEM; Carl Zeiss Ultra 55). Raman spectroscopy and X-Ray diffraction are also carried out ex-situ at room temperature on the resulting samples. Sample corresponding to nucleation step (catalyst nanoparticles and few nucleating CNT) was analysed by Raman spectroscopy first on its top surface and second in the depth of nanoparticles initiating CNT growth (one spectrum every $230 \mathrm{~nm}$ ) in order to evaluate the carbon changes along nanoparticle agglomerates (few $\mu \mathrm{m}$ ). Sample corresponding to the growth step (CNT carpet) was analysed by Raman spectroscopy along the carpet height (one spectrum every $40-50 \mu \mathrm{m}$ ) in order to evaluate the carbon structure changes along the carpet (400 $\mu \mathrm{m}$ thick). Therefore, Raman analysis scale along nanoparticles (nucleation step) is more local as compared to the one performed in the case of carpet (growth step). 
Raman spectroscopy was performed with a commercial Witec Alpha 500 spectrometer in a back-scattering configuration. We used excitation wavelengths at $532 \mathrm{~nm}$ from a solid state laser diode. The power of the laser beam was kept below $600 \mu \mathrm{W}$ to prevent any damage on the A-MWNT carpet. All Raman spectra were recorded with a Nikon x50 objective $(\mathrm{NA}=0.75)$ focusing the light with a $350 \mathrm{~nm}$ diameter spot. A dual axis $\mathrm{XY}$ piezo stage coupled to a confocal microscope allows mapping Raman intensity with subwavelength accuracy (ca. $120 \mathrm{~nm}$ ) and in the $\mathrm{Z}$ direction with accuracy of about $350 \mathrm{~nm}$. Raman spectra are recorded on each pixel and the integrated intensity of a chosen mode is displayed on a false color scale.

Furthermore, spectral resolutions of our spectrometer (UHTS300) are (i) $<3 \mathrm{~cm}^{-1}$ (ie 0.009 $\mathrm{nm}$ ) with a 600 grooves $/ \mathrm{mm}$ grating and (ii) $<0.9 \mathrm{~cm}^{-1}$ (ie $0.025 \mathrm{~nm}$ ) with a 1800 grooves/mm grating. In this paper, maps are performed with a 600 grooves/mm grating and spectra with a 1800 grooves/mm grating.

X-Ray diffraction experiments were performed on two different setups:

(i) microdiffraction measurements are performed with a monochromatic $\mathrm{Cu}-\mathrm{K} \alpha(\lambda=1.542 \AA)$ X-ray microbeam of $20 \mu \mathrm{m}$ diameter size obtained with a multilayer optics coupled with a laboratory rotating-anode generator [23]. The 2D direct-illumination CCD detector allows to measure weak scattering signals such as the (002) CNT peak from the carpet. Measurement along the height of the carpet with a $10 \mu \mathrm{m}$ step is performed thanks to a motorized translation stage.

(ii) standard laboratory diffraction experiments with a millimeter-size and monochromatic $\operatorname{Mo}-\mathrm{K} \alpha(\lambda=0.711 \AA)$ beam are performed in order to measure iron phases [15]. The intense $\mathrm{X}$ ray beam allows detecting the weak scattered signals from the small amounts of iron. The short Mo-K $\alpha$ wavelength gives access to a large Q wavevector domain $\left(1.5-4.5 \AA^{-1}\right)$. It also 
avoids the X-ray fluorescence background that hinders the weak signals to be observed with $\mathrm{Cu}-\mathrm{K} \alpha$ radiation.

\section{Results and discussion:}

Figure 1 shows SEM images of two different samples formed respectively during CNT nucleation step and CNT growth step on silicon substrates. The first one (sample 1) is obtained during the early growth stages of CNT formation (15 s) corresponding to CNT nucleation step (figure 1 (a)). The second one (sample 2) is obtained after a longer CCVD synthesis duration (15 min) corresponding to CNT growth step (figure 1(b)).

In figure 1 (a) (sample 1), we observe a layer of iron-based catalyst nanoparticles covering the whole silicon wafer surface, and constituting the main part of the sample. We also observe a significant amount of catalyst particle agglomerates with various dimensions from $500 \mathrm{~nm}$ to $2 \mu \mathrm{m}$ [11]. These two area (A: agglomerated particles and B: film of catalyst nanoparticles) are designed designated on figure 1(a) by two white crosses and are shown with higher magnification on figure 1(c) and (d) respectively. Some nanotubes are already occurring even for this early stage and are localized mainly on catalyst particles which are agglomerated. In figure 1 (b), large scale SEM image of sample 2 shows a typical well-aligned MWNT carpet exhibiting a thickness of $400 \mu \mathrm{m}$. These MWNT are partially filled with iron based phases as described by Pinault et al. $[11,24]$.

In this work, we emphasize first on the study of the CNT obtained during the nucleation step by performing both Raman spectroscopy and X-Ray Diffraction analysis (XRD) on sample 1 . These two techniques are complementary: Raman spectroscopy gives spatially localized information (laser spot $\sim 350 \mathrm{~nm}$ ) whereas XRD allows one to perform statistical average (XRD beam $\sim 1 \mathrm{~mm}$ for this experiment). For this sample grown during the early stages and 
thus exhibiting a low amount of carbon, Raman spectroscopy is sensitive to both iron-based and carbon phases whereas XRD is mainly sensitive to iron-based phases.

Figure 2 shows Raman spectroscopy performed on the top surface and XRD measurements on sample 1. White crosses designed in figure 1 (a) correspond to the two areas (A and B) studied by Raman spectroscopy. The first spectrum is achieved on the top surface of agglomerated catalyst particles (figure $2(\mathrm{a}, \mathrm{c})$ ) and the second one on the film of catalyst nanoparticles (figure 2 (b, d)). On particle agglomerates (figure 2), we can observe several peaks between 100 and $600 \mathrm{~cm}^{-1}$ (figure 2 (a)) and one at $1316 \mathrm{~cm}^{-1}$ (figure 2 (c)). We can assign most of them to iron oxides phases. Peaks at 226, 245, 294, 410, 610, $1316 \mathrm{~cm}^{-1}$ are due to $\alpha-\mathrm{Fe}_{2} \mathrm{O}_{3}$ whereas the one at $663 \mathrm{~cm}^{-1}$ is assigned to magnetite $\mathrm{Fe}_{3} \mathrm{O}_{4}$ [25-27] (table 1). On the film of nanoparticle, the peak positions assigned to $\alpha-\mathrm{Fe}_{2} \mathrm{O}_{3}$ are very difficult to identify whereas the peak related to $\mathrm{Fe}_{3} \mathrm{O}_{4}$ at $663 \mathrm{~cm}^{-1}$ is clearly occurring.

This assignment obtained through spatially localised analysis is in agreement with XRD analysis (Figure 2 (e)) involving statically statistically averaged information where all diffraction peaks are attributed to $\alpha-\mathrm{Fe}_{2} \mathrm{O}_{3}$ and $\mathrm{Fe}_{3} \mathrm{O}_{4}$ (calculation give us a $\alpha-\mathrm{Fe}_{2} \mathrm{O}_{3} / \mathrm{Fe}_{3} \mathrm{O}_{4}$ mass ratio $=4 / 3$, figure $2(\mathrm{e}))[11,15]$. This is the first XRD identification of $\alpha-\mathrm{Fe}_{2} \mathrm{O}_{3}$ in such samples, due probably to a too low content of such phase in previous studies $[11,15,17,19]$. The presence of iron oxides has also been reported in the case of CNT growth by CCVD [2831]. However, such oxide phases are not the catalytic phases in the process we use, where nanoparticles giving rise to CNT growth were shown to be cementite nanoparticles [22]. We have shown that the occurrence of oxides is due to iron oxidation during the cooling step [15], and the present results indicate that the oxidation is not complete for all iron-based particles since $\mathrm{Fe}_{3} \mathrm{O}_{4}$ is detected. In addition, in our study no oxygen-containing promoters such as traces of water have been added to the reactive gas phase. Catalyst particles are formed in-situ in the gas phase from ferrocene decomposition initiating quasi instantaneously the 
decomposition of toluene and liberating hydrogen in the gas-phase, thus preventing any oxidation of the different phases during CNT growth even with oxygen contamination, as shown through our in-situ study [22]. This is, therefore, not comparable to studies involving catalyst films predeposited on substrates which could be oxidized during annealing through oxygen contamination [32,33].

It is therefore important to localise and analyse the carbon structure in the same areas as the ones of iron-based particles. It is first noteworthy that in both areas (agglomerated particles or films of nanoparticles), carbon could be always detected even if it corresponds to the early stages of CNT formation and if oxidation is occurring during the cooling step, indicating that only a partial oxidation is involved which is corroborated by the occurrence of $\mathrm{Fe}_{3} \mathrm{O}_{4}$. Concerning the carbon phase, figure 2 (c) shows the Raman response measured on agglomerated catalyst particles of sample 1 . Three peaks at 1576, 1605 and $2663 \mathrm{~cm}^{-1}$ (not shown) assigned to $\mathrm{sp}^{2}$ carbon modes can be distinguished. The first one is due to the in plane bond stretching of all pairs of $\mathrm{sp}^{2}$ atoms ( $\mathrm{E}_{2 \mathrm{~g}}$ zone-centred) usually called the $\mathrm{G}$ band which is common to both rings and chains. The second one at $\sim 1605 \mathrm{~cm}^{-1}$ called $\mathrm{D}^{\prime}$, is assigned to noncentred phonons [34-36]. The inset of figure 3 (d) shows the 2D band which is the overtone of the $\mathrm{D}$ band (around $1353 \mathrm{~cm}^{-1}$ included on the large band at $1316 \mathrm{~cm}^{-1}$ which is assigned to $\alpha$ $\mathrm{Fe}_{2} \mathrm{O}_{3}$ and called $\mathrm{M}$ band in this work (see Table 1)). The $\mathrm{D}$ band is due to the breathing mode of $\mathrm{sp}^{2}$ rings [37]. Some other bands around $1100 \mathrm{~cm}^{-1}$ (figure 3 (d) and figure 4 (d-e)) and $1500 \mathrm{~cm}^{-1}$ (mode at $1412 \mathrm{~cm}^{-1}$ on figure 2 (d)) are detected which are usually observed in amorphous carbon and disappear with increasing order in $\mathrm{sp}^{2}$ carbon materials $[37,38]$. Figure 2 (d) presents Raman spectrum regarding carbon on catalyst nanoparticles film of sample 1 . As previously observed on agglomerated catalyst particles (figure 2 (c)), all carbon $\mathrm{sp}^{2}$ signatures (D, D', G and 2D bands) are present. The $\mathrm{G}$ band frequency is around $1580 \mathrm{~cm}^{-}$ ${ }^{1}$ and the D' band is around $1614 \mathrm{~cm}^{-1}$. In this spectrum, we clearly identify the D band at 
$1350 \mathrm{~cm}^{-1}$ and its overtone at $2656 \mathrm{~cm}^{-1}$ (not shown). The difference in $\mathrm{G}$ band frequency between these two areas of the sample is due to two different carbon structural organisations. The one at $1576 \mathrm{~cm}^{-1}$ occurring on the agglomerated catalyst particles, exhibiting the higher oxidation degree (presence of $\alpha-\mathrm{Fe}_{2} \mathrm{O}_{3}$ ), corresponds to the one already reported for aligned MWNT carpet [12], whereas the G band at $1580 \mathrm{~cm}^{-1}$, detected on the film of nanoparticles exhibiting a lower oxidation degree (presence of mainly $\mathrm{Fe}_{3} \mathrm{O}_{4}$ ), corresponds to the one reported for graphitic systems exhibiting a significant amount of defects [39]. These results obtained on the top surface of the two areas are corroborated by SEM images (figure 1 (a) and (c)) where we can clearly observe the occurrence of CNT on particle agglomerates while only very few CNT-like morphology are observed on the catalyst nanoparticle film.

Therefore, Raman spectroscopy reveals that on samples obtained during the nucleation step, both iron-based phases and carbon phases are together detected, even if oxidation occurs during the cooling step. In addition, the carbon structure is less defective in the areas in which $\alpha-\mathrm{Fe}_{2} \mathrm{O}_{3}$ is predominant (higher oxidation degree) while it is more defective (see $\mathrm{D}$ and $\mathrm{G}$ band intensities and frequencies in addition with the presence of a large background centered around $1400 \mathrm{~cm}^{-1}$ due to amourphous carbon) in the areas in which $\mathrm{Fe}_{3} \mathrm{O}_{4}$ is predominant (lower oxidation degree). Assuming that oxidation of carbon-encapsulated iron-based nanoparticles involves the formation of vacancies in carbon structure through the formation of $\mathrm{CO}$ or $\mathrm{CO}_{2}$ vapours and then the oxidation of iron-based nanoparticles [40, 41], the trends obtained in our study cannot be explained only by an oxidation phenomenon. Therefore, the identification by Raman spectroscopy of both iron-based and carbon phase in the same areas combined to SEM and XPS measurements [11] indicates that, as soon as iron-based catalytic nanoparticles are deposited, carbon structures organised into more or less defective $\mathrm{sp}^{2}$ carbon forming graphene sheets (Raman and XPS) and arranged concentrically (presence of nanotubes shown by SEM) are formed [11]. 
In order to go further in the analysis of the CNT nucleation step, a spatially resolved analysis of the carbonaceous structure around the catalyst particles is of high importance. This is possible thanks to the recent developments in spatially resolved Raman spectroscopy which exhibit potentialities to get Raman mapping of both the iron-based and carbon phase. Thus, we studied the spatial distribution of $\mathrm{C}$ and Fe elements on sample 1 by XY-spatially resolved Raman imaging. Raman intensity maps for iron-based phases are reported on figure 3 (a) and (b) by using the most intense peak at $226 \mathrm{~cm}^{-1}$ for $\alpha-\mathrm{Fe}_{2} \mathrm{O}_{3}$ and $663 \mathrm{~cm}^{-1}$ for $\mathrm{Fe}_{3} \mathrm{O}_{4}$. Typical spatially resolved Raman intensity maps of carbon using the $\mathrm{G}$ band are reported on figure 3 (c). In addition, the acquisition of a Raman spectrum at a determined position on the agglomerated catalyst particles (figure 3 (d)), indicates that all iron oxides and carbon phases are occurring all together.

These intensity maps (figures $3 \mathrm{a}, \mathrm{b}, \mathrm{c}$ ) demonstrate clearly that carbon and iron are localized at the same position. Indeed the intensities related to iron oxides are proportional to the one related to carbon and the maximum of their intensity corresponds to each other and to the area on which agglomerated particles are observed. Therefore, these results confirm that $\mathrm{sp}^{2}$ carbon nucleates preferentially on iron-based particles and that a high amount is more specifically located on areas in which particles are agglomerated, at least during this very early CNT growth stages. Therefore, during this early stage of CNT formation for which a steady state has, still, not been reached this result suggests that a higher amount of carbon is generated through catalytic decomposition of the carbon source in areas where the quantity of nanoparticles is predominant.

In order to go into details with these results, a depth scan in $(z, x)$ directions (figure 4) has been performed on agglomerated particles. Figure 4 (a) to (c) indicate that carbon (G band) and iron-based phases $\left(\alpha-\mathrm{Fe}_{2} \mathrm{O}_{3}\right.$ at 226 and $1316 \mathrm{~cm}^{-1}$; same results for $\mathrm{Fe}_{3} \mathrm{O}_{4}$ not shown $)$ are 
localized at the same $\mathrm{z}$ position and slightly shifted in $\mathrm{x}$ direction. This shift is in agreement with SEM observations showing that several bended CNT are growing from agglomerated particles and they are not precisely in a vertical direction (figure 1 (c)). We can directly observe the intensity variation of these two phases as a function of $\mathrm{z}$ position, that is to say according to the thickness of catalyst particles and CNT deposited on the surface.

In figure 4 (d) and (e), we present the Raman spectra of carbon recorded along the blue line (designed in figure $4(\mathrm{a}-\mathrm{c}), \mathrm{z}$ is a relative coordinate). These Raman spectra were performed at the agglomerated nanoparticle scale (very local scale as compared to the analysis along the carpet, see below). All the presented spectra along this $\mathrm{z}$ line are representative of depth scans realized on several different agglomerates, from their base to their top, of this sample. The carbon and iron structures are changing according to their location along the height of the iron oxide agglomerates. (i) From the base of the agglomerate up to around $1.5 \mu \mathrm{m}$ high, the $\mathrm{G}$ band intensity increases and simultaneously the $M$ band present gradually a shoulder corresponding to the D band (dotted arrow, figure 4 (d)). (ii) Then in the upper $1.25 \mu \mathrm{m}$, the $\mathrm{G}$ band intensity saturates whereas the $\mathrm{D}$ and $\mathrm{M}$ bands both decreases $\left(\alpha-\mathrm{Fe}_{2} \mathrm{O}_{3}\right.$ peak at $226 \mathrm{~cm}^{-1}$ decreases also).

Figure 4 (f) and (h) show changes of intensity and frequency of respectively the D and the G bands along the height of particle agglomerates containing CNT. From the base up to around 1.5 $\mu \mathrm{m}$ high, the $\mathrm{G}$ and $\mathrm{D}$ band intensities increase progressively while their frequencies decrease progressively. The increase of both $\mathrm{D}$ and $\mathrm{G}$ band intensities in conjunction with the decrease of $\mathrm{D}$ band frequency indicates the formation at the base of particles of $\mathrm{sp}^{2}$ carbon clusters as reported by Ferrari and Obraztsova [37, 39]. In addition up to around $1.5 \mu \mathrm{m}$ high, the decrease of the $\mathrm{G}$ band frequency down to $1568 \mathrm{~cm}^{-1}$ is attributed to the progressive curvature of graphene planes in carbon onion like structure [34, 39]. Then, from around 1.5 $\mu \mathrm{m}$ up to $3 \mu \mathrm{m}$, the $\mathrm{G}$ band intensity saturates while its frequency increases from $1568 \mathrm{~cm}^{-1}$ to 
$1574 \mathrm{~cm}^{-1}$. Finally, the Raman spectra on the top of the particle, corresponds to the MWNT synthesis by the process of this study [12].

Regarding the D band, the intensity is quite constant in the upper part of the agglomerate even if between 1.25 to around $1.5 \mu \mathrm{m}$ a decrease of the intensity occurs. This decrease of the D band intensity is also visible in the $\mathrm{I}_{\mathrm{D}} / \mathrm{I}_{\mathrm{G}}$ ratio indicating an improvement of the structural carbon organisation, due probably to a decrease of $\mathrm{sp}^{3} / \mathrm{sp}^{2}$ ratio [37] when CNT are growing. The ratio between the intensity of $\alpha-\mathrm{Fe}_{2} \mathrm{O}_{3}$ band (at $226 \mathrm{~cm}^{-1}$ ) and of the $\mathrm{G}$ band ehange decreases along the agglomerated catalyst particles from their base to their top. This indicates that the significant increase of the $\mathrm{G}$ band occurs while the intensity of $\alpha-\mathrm{Fe}_{2} \mathrm{O}_{3}$ (and $\mathrm{Fe}_{3} \mathrm{O}_{4}$ not shown) decreases only slightly. Thus, the base of the agglomerate is composed of low amount of $\mathrm{sp}^{2}$ carbon versus iron oxide. This amount increases progressively up to around 1 $\mu \mathrm{m}$ high and then remains stable in the upper part of the particles (Figure $4(\mathrm{~g})$ ).

Figure 4 (i) reports the $I_{D} / I_{G}$ ratio which is related to structural defects in nanotubes: the smaller this ratio is the higher the degree of crystallinity is [41, 42]. Figure 4 (i) indicates that this ratio remains almost constant (around 1) up to $1.5 \mu \mathrm{m}$ high which is the signature of the progressive increase of $\mathrm{D}$ and $\mathrm{G}$ band intensities. Then from $1.5 \mu \mathrm{m}$ up to the top of the particles, the $\mathrm{I}_{\mathrm{D}} / \mathrm{I}_{\mathrm{G}}$ ratio reaches a value of 0.5 which corresponds to a better organisation on $\mathrm{sp}^{2}$ carbon as a CNT structure.

All these depth scan analysis highlights that the structural organization of carbon changes significantly from the base of particles to their top. In the first $\mu \mathrm{m}$ at their base, Raman results indicate onion like structures with a significant amount of defects whereas in the upper parts of the particles, carbon becomes more organised. It is also important to note that the amount of $\mathrm{sp}^{2}$ carbon increases in the basal region of the particles. Defects in $\mathrm{sp}^{2}$ carbon structure occurring at the base of the particle could be explained by the metal catalysed oxidation of carbon $[40,41,44,45]$. This phenomenon could occur during the cooling step in helium gas 
containing oxygen traces since iron-based particles are converted into iron oxide particles. However, such a phenomenon should be very limited since the partial pressure of oxygen in helium is very low ( 3 ppm-mol $\mathrm{H}_{2} \mathrm{O}+2$ ppm-mol de $\mathrm{O}_{2}$ ) contrary to the oxidation studies reported in the literature for which the oxygen partial pressure is high [40, 41, 44]. According to the studies reported in the literature, air oxidation involves that a part of carbon atoms bindings with oxygen atoms leaves the sample in form of carbon monoxide or dioxide, creating vacancies in the carbon shells which serves as channels for outward diffusion of metallic core and penetration of oxygen in the interior, thus creating large size hollow $\mathrm{Fe}_{2} \mathrm{O}_{3} / \mathrm{C}_{\text {ox }}$ nanoparticles [40, 41, 44, 45]. However, in our study we could not identify neither hollow particle by electron microscopy nor carbon-oxygen bonding by Raman spectroscopy. In addition, according to the oxidation phenomenon reported in the literature, carbon should be uniformly defective all along the iron-based particle, which is not the case in our study. Therefore, the carbon structural difference occurring along the iron-based particles from their base to their top cannot be explained only by oxidation, especially because the cooling process is performed with only a very low partial pressure of oxygen as compared to literature. We believe that such changes in carbon structure along the particles indicate that the very early nucleation steps of carbon involves the formation of defective graphene layers surrounding the particles and forming cap-like morphologies. This suggests that the structure of nucleating carbon depends most probably on its location with respect to catalyst particles and that the carbon structural organisation is progressively improving from the particles up to the upper parts of CNT.

Such a behavior regarding the carbon structure around the catalyst particle analyzed at this Raman scale is difficult to compare with the literature. Papers studying locally structural changes around the catalyst particles either through in-situ TEM or XRD [46-48] are focused on the structural changes occurring on the catalyst particles and show the forming graphitic 
structure, but no quantitative analysis of the carbon structure comparable to Raman spectroscopy has been performed. In addition, literature does not report any quantitative and spatially resolved analysis of carbon structure around catalyst nanoparticles for nanotube growth.

To go further in the understanding of carbon organisation, we also perform Raman analysis in conjunction with X-Ray microdiffraction analysis on aligned MWNT carpet (sample 2) grown for longer durations (15 $\mathrm{min})$.

A Raman statistical analysis was achieved along the carpet from the base to the top (black arrow in figure 1 (b)). The scale analysis of the carpet to follow the carbon structure along the carpet is not the same that for agglomerate. The number of spectra concerning the agglomerate (size of few $\mu \mathrm{m}$ ) is close to this performed along the carpet (size of $400 \mu \mathrm{m}$ ) to have changes of carbon structure along agglomerate and along the carpet. Figure 5 (a) shows representative Raman signature of the top, the middle and the base of the carpet indicated by white rectangles on the SEM image of the carpet cross-section (figure 1 (b)). We identified on these spectra, the $\mathrm{D}, \mathrm{G}$ and $2 \mathrm{D}$ bands whatever the position along the carpet. The background of the spectra and the width of these bands are increasing near the top of the carpet. The $\mathrm{I}_{\mathrm{D}} / \mathrm{I}_{\mathrm{G}}$ ratio varies from 0.5 to 1.35 from the base to the top of the carpet (inset figure 5 (a)). The $\mathrm{I}_{\mathrm{D}} / \mathrm{I}_{\mathrm{G}}$ value for our raw sample is similar to the one reported for aligned MWNT raw samples synthesized by CVD [49] and is significantly lower than the ones generally reported for MWNT produced by CVD [50]. The values for both $\mathrm{I}_{\mathrm{D}} / \mathrm{I}_{\mathrm{G}}$ ratio and width bands are related to structural defects in nanotubes: the smaller these parameters are, the higher the degree of crystallinity is $[42,43]$. The Raman spectrum of the top shows an important background due to iron based-phases luminescence and to carbon induced-defects indicating also a higher carbon structural disorder at the top of the carpet. This could be assigned to MWNT which are quite bended and decorated with residual catalyst encapsulated by carbon (inset figure $5(\mathrm{e})$ ). 
X-Ray micro-diffraction as well as GISAXS measurements performed by different groups show the possibility to extract the degree of MWNT alignment on such a carpet $[19,51]$. In our case XRD analyses were performed in transmission from the base to the top of the carpet as indicated in figure 1 (b) by the black arrow. As reported by Pichot et al. [19], the intensity of the (002) peak at $\mathrm{Q}=1.83 \AA^{-1}$, corresponding to the scattering from the MWNT walls, is angularly modulated. By fitting this modulation, it is possible to determine the alignment degree of the CNT according to the normal of the substrate surface [21, 52]. The two Lorentzian peaks of the (002) measured in the reciprocal space correspond to the orientation distribution function in the direct space which is a Lorentzian ${ }^{3 / 2}$ [53]. Figure 5 (b) reports the orientation of MWNT according to the normal of the substrate surface by giving the Full Width at Half Maximum of this function and shows that the alignment degree is constant (+/$10^{\circ}$ according to the normal of the substrate surface) from the base of the carpet up to approximately $60 \mu \mathrm{m}$ before the top surface.

This is consistent with SEM observations showing that MWNT alignment is better at the base (figure 5 (c)) and in the core (figure 5 (d)) than at the top (figure 5 (e)) of the carpet, and that, at the top, MWNT are quite bended and decorated with particles which are most probably residual catalyst encapsulated by carbon (inset figure 5 (e)).

Therefore, more defective carbon (high $\mathrm{I}_{\mathrm{D}} / \mathrm{I}_{\mathrm{G}}$ ratio) is located by Raman spectroscopy at the top of the carpet (inset figure 5 (a)) and corresponds to bended (SEM observations) and less aligned (XRD analysis) nanotubes as well as carbon encapsulated residual catalyst particles. An improvement of the carbon structural quality (progressive decrease of $I_{D} / I_{G}$ ratio) is occurring in the core and at the base of the carpet and corresponds to quite straight, well aligned and pure nanotubes. At the base of the carpet corresponding to the place where catalyst particles are localized, i.e. in the areas in which nanotubes and catalyst particles are together present, the $I_{D} / I_{G}$ ratio reaches the lowest value of 0.5 which is similar to the value 
obtained from depth scan analysis at the top of agglomerated particles, indicating that the organisation of carbon located in the catalyst particle areas is quite high and remains similar whatever the formation stage of nanotube (nucleation or growth step). Taking into account that these aligned nanotubes are growing through a base growth mechanism [20], this result strongly suggests that the structural organisation of carbon formed around the active catalyst particles at the base of the carpet remains quite similar all along CNT nucleation and growth. The base growth mechanism of our CNT synthesized by AA-CCVD was previously described $[13,20]$, briefly the carbon species are integrated by the catalyst particles and then CNT are growing on the top of these particles, the catalyst particles remain attached at the CNT base all along the growth and are staying at the base of the carpet. Considering such a base growth mechanism, the top of the carpet is composed of nanotubes firstly formed. Therefore, we can compare their structural organisation $\left(\mathrm{I}_{\mathrm{D}} / \mathrm{I}_{\mathrm{G}}\right.$ around 1.3) to the one of CNT formed on the top of catalyst particle agglomerates during the early stages $\left(\mathrm{I}_{\mathrm{D}} / \mathrm{I}_{\mathrm{G}}\right.$ around 0.5$)$. By combining these results to SEM observations, the high $\mathrm{I}_{\mathrm{D}} / \mathrm{I}_{\mathrm{G}}$ ratio at the top of the carpet can be explained by the presence of residual catalyst particles coated with carbon and located at the CNT surface (inset figure 5 (e)) as well as amorphous carbon responsible of the important background of the Raman spectrum (black spectrum figure 5 (a)) comparatively to the flat one on the top of the particles in the sample 1 (figure 4 (e)). These contaminations (residual catalyst particles and amorphous carbon) probably appear during the cooling step of the sample; they are predominant at the top of the carpet and decrease progressively, which explain the higher $\mathrm{I}_{\mathrm{D}} / \mathrm{I}_{\mathrm{G}}$ ratio at the top of the carpet than the one at the top of the particles.

\section{Conclusions}

Spatially resolved Raman spectroscopy analyses on samples prepared during CNT nucleation stage show that it is possible to co-localise and analyse simultaneously the structure of ironbased catalyst particles and carbonaceous materials resulting from the nucleation step of 
aligned MWNT. The structural organisation of carbon changes significantly from the base of agglomerated particles to their top. At their base, Raman reveals onion like structures with a significant amount of defects suggesting that the very early nucleation steps of carbon involves the formation of defective graphene layers. Then in the upper parts of these particles, carbon becomes organised suggesting that the structure of nucleating carbon depends on its location with respect to the catalyst nanoparticle. In addition, the amount of carbon is found to be lower at the vicinity of the catalyst nanoparticle (nanotube base) and increases in the upper part of nanotube. These results are of main interest for the understanding of growth mechanism of aligned carbon nanotube, which is crucial for applications in different fields of nanotechnology.

\section{Acknowledgement}

The authors thank C'Nano Ile de France (microdiffraction detector) and C'Nano Rhône Alpes (Ti-saphire Laser), CPER Rhône-Alpes, Région Ile de France (FEG-SEM) and the french agency ANR (Alucinan project in the P-Nano program) as well as RTRA Triangle de La Physique for financial support.

\section{References}

[1] J. K. Holt, H. G. Park, Y. Wang, M. Stadermann, A. B. Artyukhin, C.P. Grigoropoulos, A. Noy, O. Bakajin, Fast Mass Transport Through Sub-2-Nanometer Carbon Nanotubes, Science 312 (2006) 1034.

[2] L. Su, X. Zhang, C. Yuan, B. Gao, Symmetric Self-Hybrid Supercapacitor Consisting of Multiwall Carbon Nanotubes and Co-Al Layered Double Hydroxides Batteries and Energy Storage, J. Electrochem. Soc. 155 (2008) A110.

[3] H. Cebeci, R. G. De Villoria, A. J. Hart, B. L. Wardle, Multifunctional properties of high volume fraction aligned carbon nanotube polymer composites with controlled morphology, COMPOS SCI TECHNOL 69 (2009) 2649.

[4] H. Peng, X. Sun, Highly aligned carbon nanotube/polymer composites with much improved electrical conductivities, Chem. Phys. Lett. 471 (2009) 103. 
[5] M. José-Yacamán, M. Miki-Yoshida, L. Rendón, J. G. Santiesteban, Catalytic growth of carbon microtubules with fullerene structure, Appl. Phys. Lett. 62 (1993) 202.

[6] G. Eres, A. A. Puretzky, D. B. Geohegan, H. Cui, In situ control of the catalyst efficiency in chemical vapor deposition of vertically aligned carbon nanotubes on predeposited metal catalyst films, Appl. Phys. Lett. 84 (2004) 1759.

[7] S. Yasuda, D. N. Futaba, T. Yamada, J. Satou, A. Shibuya, H. Takai, K. Arakawa, M. Yumura, K. Hata, Improved and Large Area Single-Walled Carbon Nanotube Forest Growth by Controlling the Gas Flow Direction, ACS Nano 3 (2009) 4164.

[8] R. Andrews, D. Jacques, A. M. Rao, F. Derbyshire, D. Qian, X. Fan, E. C. Dickey, J. Chen, Continuous production of aligned carbon nanotubes: a step closer to commercial realization, Chem. Phys. Lett. 303 (1999) 467.

[9] M. Mayne, N. Grobert, M. Terrones, R. Kamalakaran, M. Rühle, H. W. Kroto, D. R. M. Walton, Pyrolytic production of aligned carbon nanotubes from homogeneously dispersed benzene-based aerosols, Chem. Phys. Lett. 338 (2001) 101.

[10] R. Kamalakaran, M. Terrones, T. Seeger, M. Ru, Y. A. Kim, T. Hayashi, M. Endo, Synthesis of thick and crystalline nanotube arrays by spray pyrolysis, Appl. Phys. Lett. 77 (2000) 3385.

[11] M. Pinault, M. Mayne-L'Hermite, C. Reynaud, V. Pichot, P. Launois, D. Ballutaud, Growth of multiwalled carbon nanotubes during the initial stages of aerosol-assisted CCVD, Carbon 43 (2005) 2968.

[12] C. Castro, M. Pinault, S. Coste-Leconte, D. Porterat, N. Bendiab, C. Reynaud, M. Mayne-L'Hermite, Dynamics of catalyst particle formation and multi-walled carbon nanotube growth in aerosol-assisted catalytic chemical vapor deposition, Carbon 48 (2010) 3807.

[13] J-P. Tessonnier, D.S. Su, Recent Progress on the Growth Mechanism of Carbon Nanotubes: A Review, ChemSusChem 4 (2011) 824

[14] H. Kim, M. J. Kaufman, W. M. Sigmund, D. Jacques, R. Andrews, Observation and formation mechanism of stable face-centered-cubic Fe nanorods in carbon nanotubes, Journal of Materials Research 18 (2003) 1104.

[15] V. Heresanu, C. Castro, J. Cambedouzou, M. Pinault, O. Stephan, C. Reynaud, M. Mayne-L'Hermite, P. Launois, Nature of the Catalyst Particles in CCVD Synthesis of Multiwalled Carbon Nanotubes Revealed by the Cooling Step Study, J. Phys. Chem. C 112 (2008) 7371.

[16] M. Kumar, Y. Ando, Chemical Vapor Deposition of Carbon Nanotubes: A Review on Growth Mechanism and Mass Production, J Nanosci Nanotechnol 10 (2010) 3739.

[17] M. Pinault, M. Mayne-L'Hermite, C. Reynaud, O. Beyssac, J. N. Rouzaud, C. Clinard, Carbon nanotubes produced by aerosol pyrolysis: growth mechanisms and postannealing effects, Diam Relat Mater. 13 (2004) 1266. 
[18] A. Koos, M. Dowling, K. Jurkschat, A. Crossley, N. Grobert, Effect of the experimental parameters on the structure of nitrogen-doped carbon nanotubes produced by aerosol chemical vapour deposition, Carbon 47 (2009) 30.

[19] V. Pichot, P. Launois, M. Pinault, M. Mayne-L'Hermite, C. Reynaud, Evidence of strong nanotube alignment and for iron preferential growth axis in multiwalled carbon nanotube carpets, Appl. Phys. Lett. 85 (2004) 473.

[20] M. Pinault, V. Pichot, H. Khodja, P. Launois, C. Reynaud, M. Mayne-L' Hermite, Evidence of Sequential Lift in Growth of Aligned Multiwalled Carbon Nanotube Multilayers, Nano Lett. 5 (2005) 2394.

[21] V. Pichot, S. Badaire, P-A. Albouy, C. Zakri, P. Poulin, P. Launois, Structural and mechanical properties of single-wall carbon nanotube fibers, Phys. Rev. B 74 (2006) 245416-1.

[22] P. Landois, S. Rouzière, M. Pinault, D. Porterat, C. Mocuta, E. Elkaim, M. MayneL'Hermite, P. Launois, Growth of aligned multi-walled carbon nanotubes: First in situ and time-resolved X-ray diffraction analysis, Phys. Status Solidi B, 248 (2011) 2449

[23] S. Rouzière, E. Jourdanneau, B. Kasmi, P. Joly, D. Petermann, P-A. Albouy, A laboratory X-ray microbeam for combined X-ray diffraction and fluorescence measurements, J Appl Crystallogr. 43(5) (2010) 1131.

[24] B. Bouchet -Fabre, M. Pinault, V. Pichot, P. Launois, M. Mayne-L'Hermite, P. Parent, K. Laffon, D. Durand, C. Reynaud, NEXAFS and X-ray scattering study of structure changes after post-annealing treatments of aligned MWNTs, Diam Relat Mater. 14 (2005) 881.

[25] D. L. A. de Faria, S. Venâncio Silva, M. T. de Oliveira, Raman microspectroscopy of some iron oxides and oxyhydroxides, J. Raman Spectrosc. 28 (1997) 873.

[26] S. J. Oh, D. C. Cook, H. E. Townsend, Characterization of Iron Oxides Commonly Formed as Corrosion Products on Steel, Hyperfine Interact. 112 (1998) 59.

[27] A. G. Nasibulin, S. Rackauskas, H. Jiang, Y. Tian, P. R. Mudimela, S. D. Shandakov, L. I. Nasibulina, J. Sainio, E. I. Kauppinen, Simple and rapid synthesis of $\alpha-\mathrm{Fe}_{2} \mathrm{O}_{3}$ nanowires under ambient conditions, Nano Res. 2 (2009) 373.

[28] S. Fan, G. Chapline, N. R. Franklin, T. W. Tombler, A. M. Cassell, H. Dai, SelfOriented Regular Arrays of Carbon Nanotubes and Their Field Emission Properties, Science 283 (1999) 512.

[29] P. Mauron, C. Emmenegger, A. Züttel, C. Nützenadel, P. Sudan, L. Schlapbach, Synthesis of oriented nanotube films by chemical vapor deposition, Carbon 40 (2002) 1339.

[30] M. C. Schnitzler, A. J. G. Zarbin, Utilization of iron oxide film obtained by CVD process as catalyst to carbon nanotubes growth, J. Solid State Chem. 182 (2009) 2867. 
[31] J. Dijon, P. D. Szkutnik, A. Fournier, T. Goislard de Monsabert, H. Okuno, E. Quesnel, V. Muffato, E. De Vito, N. Bendiab, A. Bogner, N. Bernier, How to switch from a tip to base growth mechanism in carbon nanotube growth by catalytic chemical vapour deposition, Carbon 48 (2010) 3953.

[32] B. C. Bayer, S. Hofmann, C. Castellarin-Cudia, R. Blume, C. Baehtz, S. Esconjauregui, C. T. Wirth, R. A. Oliver, C. Ducati, A. Knop-Gericke, R. Schlögl, A. Goldoni, C. Cepek, and J. Robertson, Support-Catalyst-Gas Interactions during Carbon Nanotube Growth on Metallic Ta Films, J. Phys. Chem. C, 2011, 115, 4359-4369

[33] C. R. Oliver, E. S. Polsen, Eric R. Meshot, S. Tawfick, S. J. Park, M. Bedewy, and A. J. Hart. Statistical Analysis of Variation in Laboratory Growth of Carbon Nanotube Forests and Recommendations for Improved Consistency, ACS Nano, 2013, 7, 35653580 .

[34] M. S. Dresselhaus, G. Dresselhaus, M. Cardona, G. Güntherodt, Light scattering in graphite intercalation compounds, Eds. Springer Berlin, 1982; p. 121.

[35] P. C. Eklund, J. M. Holden, R. A. Jishi, Vibrational modes of carbon nanotubes; Spectroscopy and theory, Carbon 33 (1995) 959.

[36] C. Thomsen, S. Reich, H. Jantoljak, I. Loa, K. Syassen, M. Burghard, G. S. Duesberg, S. Roth, Raman spectroscopy on single- and multi-walled nanotubes under high pressure, Appl. Phys. A Mater. Sci. Process. 69 (1999) 309.

[37] A. C. Ferrari, J. Robertson, Interpretation of Raman spectra of disordered and amorphous carbon, Phys. Rev. B 61 (2000) 14095.

[38] P. Tan, C. Hu, J. Dong, W. Shen, B. Zhang, Polarization properties, high-order Raman spectra, and frequency asymmetry between Stokes and anti-Stokes scattering of Raman modes in a graphite whisker, Phys. Rev. B 64 (2001) 214301.

[39] E. D. Obraztsova, M. Fujii, S. Hayashi, V. L. Kuznetsov, Y. V. Butenko, A. L. Chuvilin, Raman identification of onion-like carbon, Carbon 36 (1998) 821.

[40] X. Feng, S.W. Chee, R. Sharma, K. Liu, X. Xie, Q. Li, S. Fan, K. Jiang, In Situ TEM observation of the gasification and growth of carbon nanotubes using iron catalysts, Nano Res. 4(8) (2011) 767

[41] Y.V. Fedoseeva, L.G. Bulusheva, A.V. Okotrub, D.V. Vyalikh, J. Huo, H. Song, J. Zhou, X. Chen, Effect of oxidation and heat treatment on the morphology and electronic structure of carbon-encapsulated iron carbide nanoparticles, Mater. Chem. Phys., 135 (2012) 235

[42] F. Tunistra, J. L. Koenig, Raman Spectrum of Graphite, J. Chem. Phys 53 (1970) 1126.

[43] P. Tan, L. An, L. Liu, Z. Guo, R. Czerw, D. Carroll, P. Ajayan, N. Zhang, H. Guo, Probing the phonon dispersion relations of graphite from the double-resonance process of Stokes and anti-Stokes Raman scatterings in multiwalled carbon nanotubes, Phys. Rev. B 66 (2002) 245410. 
[44] J. Zhou, H. Song, X. Chen, J. Huo, Diffusion of Metal in a Confined Nanospace of Carbon Nanotubes Induced by Air Oxidation, J. Am. Chem. Soc. 132 (2010) 11402

[45] T.J. Booth, F. Pizzocchero, H. Andersen, T.W. Hansen, J.B. Wagner, J.R. Jinschek, R.E. Dunin-Borkowski, O. Hansen, P. Boggild, Discrete Dynamics of Nanoparticle Channelling in Suspended Graphene, Nano Lett. 11 (2011) 2689

[46] H. Yoshida, S. Takeda, T. Uchiyama, H. Kohno and Y. Homma, Atomic-Scale In-situ Observation of Carbon Nanotube Growth from Solid State Iron Carbide Nanoparticles, Nano Lett. 8, (2008) 2082

[47] C. T. Wirth, B. C. Bayer, A. D. Gamalski, S. Esconjauregui, R. S. Weatherup, C. Ducati, C. Baehtz, J. Robertson, and S. Hofmann, The Phase of Iron Catalyst Nanoparticles during Carbon Nanotube Growth, Chem. Mater.24, (2012) 4633

[48] R. Sharma, E. Moore, P. Rez and M. M. J. Treacy, Site-Specific Fabrication of Fe Particles for Carbon Nanotube Growth, Nano Lett. 9 (2009) 689

[49] H. Amara, C. Bichara, F. Ducastelle, Interaction of carbon clusters with Ni(llll 00 ): Application to the nucleation of carbon nanotubes, Surf. Sci. 602 (2008) 77.

[50] C. Singh, M. S. P. Shaffer, K. K. K. Koziol, I. A. Kinloch, A. H. Windle, Towards the production of large-scale aligned carbon nanotubes, Chem. Phys. Lett. 372 (2003) 860.

[51] E. R. Meshot, E.Verploegen, M. Bedewi, S. Tawfick, A. R. Woll, K. S. Green, M. Hromalik, L. J . Koerner, H. T. Philipp, M. W. Tate, S.M. Gruner, A. J. Hart, HighSpeed in Situ X-ray Scattering of Carbon Nanotube Film Nucleation and SelfOrganization, ACS Nano 6 (2012) 5091.

[52] K. Nakamura, M. Fujitsuka, M. Kitajima, Disorder-induced line broadening in firstorder Raman scattering from graphite, Phys. Rev. B 41 (1990) 12260.

[53] V. Pichot, Thesis : Etudes structurales par diffusion des rayons X d'une assemblée de nanotubes de carbone alignés. relation avec les mécanismes de croissance et les propriétés Physiques- Université Paris Sud, 2005. 


\section{Tables}

Table 1. Raman wavenumbers of iron oxide phases (most intense peaks are underlined).

\begin{tabular}{|l|l|l|}
\hline Iron oxides & Wavenumbers from literature $\left(\mathrm{cm}^{-1}\right)$ & Our experiments $\left(\mathrm{cm}^{-1}\right)$ \\
\hline$\alpha-\mathrm{Fe}_{2} \mathrm{O}_{3}$ & $\underline{225}, 245,295,415,500,615,1320$ & $226,245,294,410,-610,1316$ \\
\hline $\mathrm{Fe}_{3} \mathrm{O}_{4}$ & $616, \underline{663}$ & 663 \\
\hline
\end{tabular}




\section{Figure captions}

Figure 1- SEM images of (a) sample 1 illustrating the early growth stages of CNT formation corresponding to CNT nucleation step showing two areas A: agglomerated particles (c), and B: film of catalyst nanoparticles (d) - and (b) sample 2 obtained after a longer CCVD duration corresponding to CNT growth step.

Figure 2 - Raman spectra on sample 1 localized on catalyst particle agglomerates nanoparticles (a, c) and on the layer of catalyst nanoparticles (b, d); spectra are acquired with a 1800 grooves/mm grating - XRD pattern and calculation (with a $\alpha-\mathrm{Fe}_{2} \mathrm{O}_{3} / \mathrm{Fe}_{3} \mathrm{O}_{4}$ mass ratio $=4 / 3)$ on the same sample 1 with $*$ for $\alpha-\mathrm{Fe}_{2} \mathrm{O}_{3}$ and + for $\mathrm{Fe}_{3} \mathrm{O}_{4}(\mathrm{e})-(\mathrm{Si}=$ silicon contamination of the wafer supporting the sample).

Figure 3- Bi-dimensional (x y) Raman mapping of sample 1 for $\alpha-\mathrm{Fe}_{2} \mathrm{O}_{3}$ (a), $\mathrm{Fe}_{3} \mathrm{O}_{4}$ (b) and $\mathrm{G}$ band (c) - (d) Raman spectrum of the area localized by the white cross on the maps. For this figure, maps are performed with a 600 grooves/mm grating.

Figure 4 - Bi-dimensional (x z) Raman mapping of sample 1 for $\alpha-\mathrm{Fe}_{2} \mathrm{O}_{3}$ at $226 \mathrm{~cm}^{-1}$ (a), $\alpha$ $\mathrm{Fe}_{2} \mathrm{O}_{3}$ at $1316 \mathrm{~cm}^{-1}$ (denoted $\mathrm{M}$ band) (b) and $\mathrm{G}$ band (c) with a 600 grooves $/ \mathrm{mm}$ grating Raman spectra (d) and (e) along the blue line (performed at 1800 grooves/mm grating) designed on maps - Evolution of the intensity and frequency of the D band (f) and G band (h), $\mathrm{I}_{\mathrm{Fe} 2 \mathrm{O} 3} / \mathrm{I}_{\mathrm{G}}$ ratio $(\mathrm{g})$ and $\mathrm{I}_{\mathrm{D}} / \mathrm{I}_{\mathrm{G}}$ ratio (i) along the blue line.

Figure 5 - (a) Raman spectra (1800 grooves/mm grating) - (b) Micro-diffraction analysis: Evolution of Half Width at Half Maximum (HWHM) of the CNT orientation distribution function along the carpet height. The zero position corresponds to the carpet base. The silicon substrate masks the measurements on the first 50 microns - (c, d, e) SEM images on the base (green), the middle (red) and the top (black) of a well aligned MWNT carpet. 